\title{
Tannic Acid Radicals in the Presence of Alkali Metal Salts and Their Impact on the Formation of Silicate-Phenolic Networks
}

\author{
Florian Weber, Einar Sagstuen, Qi-Zhi Zhong, Tian Zheng, and Hanna Tiainen* \\ Cite This: https://dx.doi.org/10.1021/acsami.0c16946 \\ Read Online
}

ABSTRACT: Polyphenolic molecules have become attractive building blocks for bioinspired materials due to their adhesive characteristics, capacity to complex ions, redox chemistry, and biocompatibility. For the formation of tannic acid (TA) surface modifications based on silicate-phenolic networks, a high ionic strength is required. In this study, we investigated the effects of $\mathrm{NaCl}, \mathrm{KCl}$, and $\mathrm{LiCl}$ on the formation of TA coatings and compared it to the coating formation of pyrogallol (PG) using a quartz-crystal microbalance. We found that the substitution of $\mathrm{NaCl}$ with $\mathrm{KCl}$ inhibited the TA coating formation through the high affinity of $\mathrm{K}^{+}$to phenolic groups resulting in complexation of TA. Assessment of the radical formation of TA by electron paramagnetic resonance spectroscopy showed that $\mathrm{LiCl}$ resulted in hydrolysis of
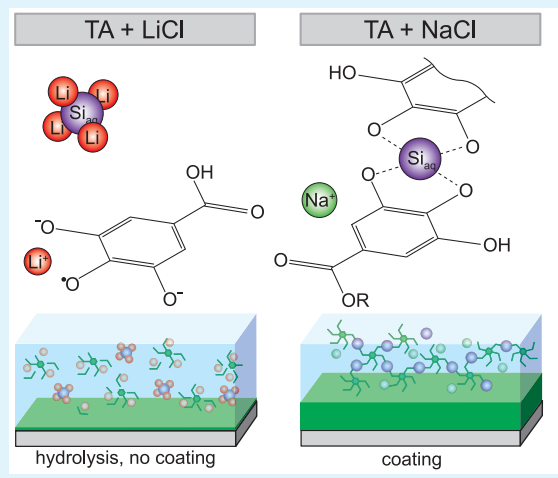

$\mathrm{TA}+\mathrm{KCl}$

$\mathrm{TA}$ forming gallic acid radicals. Further, we found evidence for interactions of $\mathrm{LiCl}$ with the $\mathrm{Si}_{\mathrm{aq}}$ crosslinker. In contrast, the coating formation of PG was only little affected by the substitution of $\mathrm{NaCl}$ with $\mathrm{LiCl}$ or $\mathrm{KCl}$. Our results demonstrate the interaction potential between alkali metal salts and phenolic compounds and highlight their importance in the continuous deposition of silicatephenolic networks. These findings can be taken as guidance for future biomedical applications of silicate-phenolic networks involving monovalent ions.

KEYWORDS: polyphenols, surface modification, nanocoating, metal-phenolic networks, EPR

\section{INTRODUCTION}

Naturally derived polyphenolic molecules have attracted great interest in creating novel and sustainable biomaterials based on green chemistry. ${ }^{1-5}$ Their versatile interaction with interfaces originates from their molecular structure featuring catechol and galloyl groups that present an opportunistic reaction site for metal coordination and surface adhesion. Further, polyphenolic coatings can be utilized to create multifunctional surfaces via subsequent modifications, e.g., Michael additions. ${ }^{4,6}$ Currently, the anti-oxidant properties of polyphenols are studied to create anti-inflammatory and anti-biofouling surfaces. ${ }^{7-10}$ In these biologically relevant environments, salts are not only an important factor for biomolecular processes but also interact with polyphenolic molecules. ${ }^{11}$

Generally, the self-assembly and deposition process of polyphenolic layers depend on the type of polyphenol. ${ }^{12}$ While tannic acid (TA) layers are commonly obtained through interaction with metal ions creating metal-phenolic networks (MPNs), ${ }^{13}$ flavonoids, and low molecular weight polyphenols, such as dopamine and pyrogallol (PG), rely on oxidative polymerization. ${ }^{14}$ Oxidation of phenolic molecules by dissolved oxygen results in their respective quinone form and is usually controlled by the solution $\mathrm{pH} .{ }^{15,16}$ Via oxidant induction or control of the $\mathrm{pH}$, the coating formation of polyphenolic molecules can be regulated. ${ }^{7,17}$ Additionally, diverse secondary interactions, such as $\pi$-stacking, $\pi$-cation interaction, hydrogen bonding, and electrostatic interactions affect the intermolecular interactions of polyphenols. ${ }^{18}$ Therefore, the formation process is also controlled by the ionic strength. Optimal conditions to create MPNs and phenolic coatings were reported to be slightly alkaline with an ionic strength $\geq 0.5 \mathrm{M}^{1,19}$

Since multivalent ions strongly complex polyphenolic molecules and rapidly precipitate high molecular weight compounds, such as $\mathrm{TA}^{20} \mathrm{NaCl}$ has been used to adjust the ionic strength in recent studies. ${ }^{1,12,17,21,22}$ More focused investigations have later shown that the film thickness and particle morphology of TA-Fe ${ }^{\mathrm{III}}$ based $\mathrm{MPNs}$ are highly dependent on the $\mathrm{NaCl}$ concentration. This relation has been attributed to changes in the hydration shell around the TA complexes. ${ }^{23}$ Subsequently, the effect of other ions on TA-Fe ${ }^{\text {III }}$ networks was refined by Park et al., who concluded that the

Received: September 20, 2020

Accepted: November 9, 2020 
optimum ionic strength depends on the type of ion and decreases for ions with higher valency and atomic radius due to proposed charge screening effects. ${ }^{24}$ Besides these charge screening effects, ions may also influence the reaction chemistry of phenolic compounds. The different interaction potentials of anions and cations with phenolic structures could influence the intermediary radical structures during oxidative polymerization reactions of polyphenols. ${ }^{25-29}$ Evidence for changes in radical structures has been obtained studying the differences in quinone radicals generated by oxidation via horseradish peroxidase and $\mathrm{H}_{2} \mathrm{O}_{2}$ or $\mathrm{NaOH}$ oxidation. ${ }^{30-32}$ In addition, stabilization of phenolic radicals by $\mathrm{Zn}^{2+}$ and $\mathrm{Mg}^{2+}$ are known effects. ${ }^{33,34}$

In this study, we investigated the interaction of silicatephenolic networks with monovalent ions, $\mathrm{Li}^{+}, \mathrm{Na}^{+}$, and $\mathrm{K}^{+}$to optimize coating conditions and to elucidate the effect of their salts on the deposition of TA coatings. Using electron paramagnetic resonance (EPR), we probed different intermediary radical structures of TA in the presence of $\mathrm{NaCl}, \mathrm{KCl}$, and $\mathrm{LiCl}$. A comparison to the formation of silica independent PG coatings allowed us to point out the specific interactions of the investigated salts with TA. We expect that these insights may impact future biomaterial research, which employs polyphenolic molecules as structural building blocks and comprise the use of monovalent ions in biological buffers.

\section{MATERIALS AND METHODS}

Materials. Tannic acid (MW $=1701.2$, LOT\#MKBN9606 V), pyrogallol $(\mathrm{MW}=126.1)$, gallic acid $(\mathrm{MW}=170.1)$, ellagic acid $(\geq 95 \%$, MW $=302.2)$, penta-galloyl glucose $(\geq 96 \%$, MW $=940.7)$, HEPES (BioPerformance, $\geq 99.5 \%$ ), $\mathrm{LiCl}, \mathrm{LiOH}, \mathrm{KCl}, \mathrm{KOH}$, sodium metasilicate pentahydrate (orthosilicic acid, $\geq 95 \%$ ), sodium persulfate $\left(\mathrm{Na}_{2}\left(\mathrm{SO}_{4}\right)_{2}, \geq 98 \%\right)$, and periodic acid $\left(\mathrm{H}_{5} \mathrm{IO}_{5}, 99 \%\right)$ were purchased from Sigma-Aldrich. $\mathrm{NaCl}$ and $\mathrm{NaOH}$ were supplied by VWR. Sodium 3-(trimethylsilyl)propionate (TMSP, 2,2,3,3-D4, D = 98\%) was supplied by Cambridge Isotope Laboratories. Ammonium molybdate (para)tetrahydrate (99\%) was purchased from Alfa Aesar. Unless otherwise stated, all materials were ACS grade.

Polyphenolic Solutions. TA and PG were dissolved at a concentration of $1 \mathrm{mg} / \mathrm{mL}$ in Milli- $Q$ water $(18 \mathrm{M} \Omega \mathrm{cm})$ containing $600 \mathrm{mM} \mathrm{NaCl}, \mathrm{KCl}$, or $\mathrm{LiCl}$ if not further specified. To avoid the influence of buffer molecules in spectroscopic techniques employed in this study, the $\mathrm{pH}$ was adjusted with specific amounts of $10 \mathrm{M}$ base added to the solutions (Table 1). More data points can be found in Figure S1 of the ESI.

Table 1. Correlation of $\mathrm{pH}$ and Added Base to Aqueous Polyphenol Solutions

$\begin{array}{ccccc}V_{\text {loMbase }}[\mu \mathrm{L} / \mathrm{mL}] & 0 & 0.3 & 0.5 & 1.0 \\ \mathrm{pH}_{\text {TAsolution }} & \sim 4 & \sim 8 & \sim 9 & \sim 11 \\ \mathrm{pH}_{\text {PGsolution }} & \sim 7 & \sim 8 & \sim 9 & \sim 11\end{array}$

Coating Deposition. To compare the coating formation with previous experiments, TA and PG coatings were dissolved in $100 \mathrm{mM}$ HEPES buffer containing $600 \mathrm{mM} \mathrm{NaCl}, \mathrm{KCl}$, or $\mathrm{LiCl}$. The buffers were adjusted to $\mathrm{pH} 7.8$ with $\mathrm{NaOH}, \mathrm{KOH}$, or $\mathrm{LiOH}$, respectively. To form silicate-TA coatings, $80-100 \mu \mathrm{M}$ orthosilicic acid $\left(\mathrm{Si}_{\mathrm{aq}}\right)$ was added. $\varnothing 6$ $\mathrm{mm}$ Ti coins were coated in $10 \mathrm{~mL}$ solutions under agitation at $30 \mathrm{rpm}$.

The real-time formation of polyphenolic coatings on $\mathrm{Ti}$ was monitored using a QSense E4 (Biolin Scientific) quartz crystal microbalance (QCM-D). Ti sensors (QSX 310, Biolin Scientific) were cleaned according to the manufacturer's protocol before and after each experiment. The procedure includes sonication in $2 \%$ SDS, washing with Milli- $\mathrm{Q}$ water and $\mathrm{EtOH}$, and finally UV-ozone treatment. The QCM-D chambers were cleaned with $2 \%$ SDS for $10 \mathrm{~min}$ at 0.5 $\mathrm{mL} / \mathrm{min}$ and extensively flushed with water $(>15 \mathrm{~min})$ prior to the experiment. Before the adsorption of polyphenols, sensors were equilibrated in the respective solvent for $20 \mathrm{~min}$, and a baseline was recorded. The polyphenol solutions were gently stirred $(100 \mathrm{rpm})$ during the measurement to provide sufficient $\mathrm{O}_{2}$. Measurements were performed at a flow rate of $0.1 \mathrm{~mL} / \mathrm{min}$ at $21^{\circ} \mathrm{C}$. After the adsorption, the sensors and chambers were flushed with Milli- $\mathrm{Q}$ water and $0.1 \mathrm{M}$ $\mathrm{HCl}$ for $5 \mathrm{~min}$ to remove the coating. All experiments were performed in triplicates $(n=3)$. Changes in frequency $(\Delta F)$ and dissipation $(\Delta D)$ were continuously monitored for the fundamental frequency and the 3rd, 5th, 7th, and 9th harmonic overtone. For clarity, only the first three harmonics are plotted. Calculations of the layer thickness were performed with QTools Software (BiolinScientific, Version 3.1.33) using the Voigt extended viscoelastic model. Fits were obtained based on the first three harmonic overtones and a power based shear dependence. The TA and PG layer densities were assumed to be 1046 and $1435 \mathrm{~kg} / \mathrm{m}^{3}$, respectively. Fluid density was set to $1027 \mathrm{~kg} / \mathrm{m}^{3}{ }^{32}$ Reported values should be taken as guidance.

Adhesion Force. Ti substrates (Ø6 mm coins) were coated for $24 \mathrm{~h}$ in $10 \mathrm{~mL}$ of HEPES buffer $(\mathrm{pH} 6.8)$ containing $1 \mathrm{mg} / \mathrm{mL} \mathrm{TA}, \mathrm{Si}_{\mathrm{aq}}$, and $600 \mathrm{mM} \mathrm{NaCl}$. Then $10.28 \mu \mathrm{m}$ polystyrene (PS) particles $(100 \mu \mathrm{L}$, $10 \%$ w/v, Microparticles $\mathrm{GmbH}$ ) were washed with $900 \mu \mathrm{L}$ of Milli-Q water three times by centrifugation $(1500 \mathrm{~g}, 60 \mathrm{~s})$ and removing of the supernatant. Subsequently, PS particles were incubated under constant stirring (400 rpm, $6 \mathrm{~h}$ ) in $1 \mathrm{~mL}$ of TA solution $(2 \mathrm{mg} / \mathrm{mL}$ TA in HEPES buffer $\mathrm{pH} 7.0$ containing $600 \mathrm{mM} \mathrm{NaCl}$ and $\mathrm{Si}_{\mathrm{aq}}$ ). Then $500 \mu \mathrm{L}$ aliquots of the dispersion were withdrawn into $1.7 \mathrm{ml}$ plastic tubes and washed with Milli-Q water three times.

To attach a PS particle on a cantilever, the tipless MLCT-O10 cantilever (Bruker, spring constant $\sim 0.03 \mathrm{~N} / \mathrm{m}$ ) was lowered into a small amount of adhesive (two-part epoxy adhesive, Super Glue Corporation, U.S.A.) that was then promptly used to pick up a colloidal PS particle deposited on a glass slide. The modified cantilever was left at room temperature to allow the adhesive to dry and set for $24 \mathrm{~h}$.

The atomic force microscopy (AFM) measurements were carried out by Cypher ES (Asylum Research, U.S.A.) with a colloidal probe in liquid. Prior to the measurement, both the TA coated Ti substrate and the colloidal probe were incubated in solutions for $10 \mathrm{~min}$ to reach equilibrium state. The spring constant of the colloidal probe was calibrated before taking force measurements. During the measurement, both the approaching and retracting velocity were kept at $500 \mathrm{~nm} / \mathrm{s}$. Between measurements in different solutions, the cantilever was washed with Milli-Q water and carefully dried to remove any residue on the colloidal probe. For each sample, at least 100 force curves were analyzed using Igor Pro 6.37.

Radical Formation. Electron paramagnetic resonance (EPR) spectra of polyphenolic radicals were recorded on a Bruker EleXsyS 560 SuperX X-band spectrometer using $25 \mu \mathrm{L}$ quartz microcapillaries (Blaubrand, intraMark) inserted in a $4 \mathrm{~mm}$ Wilmad quartz tube positioned in the cavity by a Teflon rod. For all experiments, an ER4122SHQE cavity was used. The spectra were obtained at $0.50 \mathrm{~mW}$ input microwave power (i.e. $26 \mathrm{~dB}$ power attenuation), receiver gain of $55 \mathrm{~dB}, 0.01 \mathrm{mT}$ modulation amplitude, a time constant of $81.92 \mathrm{~ms}$, and a sweep time of $83.89 \mathrm{~s}$. The magnetic field sweep width was $1 \mathrm{mT}$ with a resolution of $1 \mathrm{k}$ points. Polyphenols were dissolved $1 \mathrm{~h}$ prior to the measurements. The $\mathrm{pH}$ was adjusted $1 \mathrm{~min}$ before each experiment under gentle agitation. Details on radical modeling can be found in the Supporting Information (SI). The signs of the hyperfine coupling (HFC) constant cannot be inferred from the experimental data; hence, only the absolute values are presented here.

Spectroscopic Structure Elucidation. Fourier Transform Infrared (FTIR) Spectroscopy. Identification of functional groups was performed with a PerkinElmer Spectrum 400 using a universal attenuated total reflection (ATR) sampler. Droplets of polyphenolic solutions were evaporated on the ATR crystal. Solutions containing $\mathrm{LiCl}$ did not fully dry and a $\mathrm{LiCl} \cdot \mathrm{H}_{2} \mathrm{O}$ background had to be subtracted (Figure S2). Spectra were recorded at a resolution of $4 \mathrm{~cm}^{-1}$ and averaged over 16 measurements to improve the signal-to-noise ratio. The data was processed by correction for ATR, baseline subtraction, and normalization to the most intense peak at $1200 \mathrm{~cm}^{-1}$. 

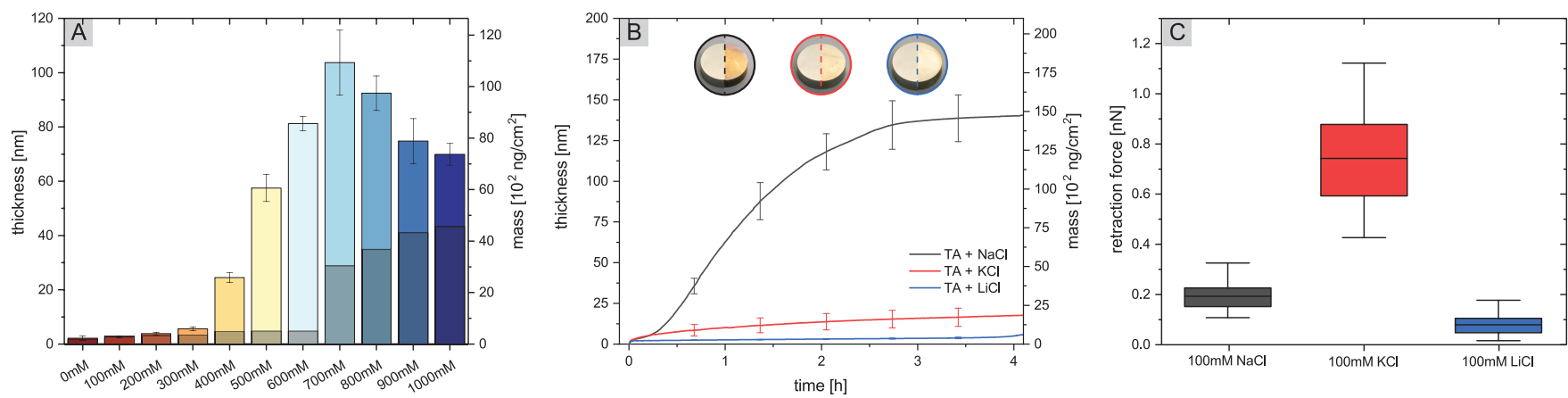

Figure 1. (A) Thickness and areal mass of tannic acid films deposited on Ti surfaces for $1 \mathrm{~h}$ determined by QCM-D. TA was dissolved in water supplemented with varying amount of $\mathrm{NaCl}, 80 \mu \mathrm{MSi}_{\mathrm{aq}}$ at $\mathrm{pH} 8(n=3)$. Control experiments without $\mathrm{Si}_{\mathrm{aq}}$ are given in grey overlays. (B) Progression of thickness and areal mass during the coating process of TA followed by QCM-D $(n=3)$. TA was dissolved in $100 \mathrm{mM}$ HEPES containing $600 \mathrm{mM}$ salt and $100 \mu \mathrm{M} \mathrm{Si}_{\mathrm{aq}}$ at $\mathrm{pH}$ 7.8. Insets show coated Ti coins (right). (C) Surface force between two TA coatings upon retraction of the AFM cantilever in $100 \mathrm{mM}$ salt solutions. For each solution, 100 data points were collected. Boxplots show 25/75 percentiles, minima, maxima, and mean values.

UV-vis Spectroscopy. The electronic state of polyphenols was determined with a PerkinElmer Lambda 25 spectrophotometer using a quartz cuvette with $10 \mathrm{~mm}$ path length. Spectra were recorded at a resolution of $1 \mathrm{~nm}$. Due to the high UV absorbance of polyphenolic molecules, $100 \times$ diluted samples were measured in the range of $220-$ $400 \mathrm{~nm}$.

Nuclear Magnetic Resonance (NMR) Spectroscopy. Solution ${ }^{13} \mathrm{C}$ NMR was performed on a Bruker AVII 600 instrument using $5 \mathrm{~mm}$ NMR tubes. Native TA was dissolved in heavy water $\left(\mathrm{D}_{2} \mathrm{O}\right)$ at $100 \mathrm{mg} /$ $\mathrm{mL}$ with TMSP as the internal reference. TA in the presence of $600 \mathrm{mM}$ salts was dissolved in $\mathrm{H}_{2} \mathrm{O}$ containing 10 vol. $\% \mathrm{D}_{2} \mathrm{O}$ due to solubility issues in pure $\mathrm{D}_{2} \mathrm{O}$. The concentration of $\mathrm{Si}_{\mathrm{aq}}(8 \mathrm{mM})$ was stoichiometrically adjusted to the concentration of TA $(100 \mathrm{mg} /$ $\mathrm{mL}$ ). Spectra were recorded at $150 \mathrm{MHz}, 90^{\circ}$ pulse, $0.9 \mathrm{~s}$ acquisition time, and $10 \mathrm{~s}$ delay time $\left(d_{1}\right)$. Solution ${ }^{29} \mathrm{Si}$ NMR was performed on a Bruker AVII 400 instrument. $\mathrm{Si}_{\mathrm{aq}}$ was dissolved at a concentration of 0.1 $\mathrm{M}$ in water containing 10 vol. $\% \mathrm{D}_{2} \mathrm{O}$ and TMSP as internal reference. Spectra were recorded at $79.5 \mathrm{MHz}, 1.0 \mathrm{~s}$ acquisition time, and $5.0 \mathrm{~s}$ delay time $\left(d_{1}\right)$.

Liquid Chromatography-Mass Spectrometry (LC-MS). TA solutions were separated from salts in a C18 SPE by washing with $10 \%$ formic acid and elution with acetonitrile. Then $1 \mu \mathrm{L}$ aliquots were injected into a high-performance liquid chromatography system (HPLC) coupled to a 6495 triple quadrupole (TQ) MS (Agilent Technologies, Singapore) via an electrospray interface. The reversephase separation was performed at a flow rate of $0.6 \mathrm{~mL} / \mathrm{min}$ on a $\mathrm{C} 18$ column (2.6 $\mu \mathrm{m}$ particle size, $3 \mathrm{~mm}$ inner diameter, $100 \mathrm{~mm}$ length, Kinetex) using water/formic acid $(0.1 \% \mathrm{v} / \mathrm{v})$ as solvent $\mathrm{A}$ and acetonitrile as solvent $\mathrm{B}$ in a stepwise gradient at $40{ }^{\circ} \mathrm{C}: 10-50 \% \mathrm{~B}(0-$ $6 \mathrm{~min}), 50-100 \% \mathrm{~B}(6-6.5 \mathrm{~min})$, held at $100 \% \mathrm{~B}$ for $1 \mathrm{~min}$. MS spectra were recorded in negative mode.

TA Purification. TA was purified on a Biotage Selekt system using a Sfär C18 Duo (100 $\AA, 30 \mu \mathrm{m}, 60 \mathrm{~g})$ column. The same eluents as described above were used to run the gradient: $5 \% \mathrm{~B}$ ( $0-2 \mathrm{~min}), 5-$ $45 \%$ B ( $2-5 \mathrm{~min})$, and 100\% B (5-10 min). The solvent was removed under reduced pressure and the TA fraction was re-dissolved in water and freeze-dried. Mass spectra were obtained using ESI-QTOF (maXis II ETD) in positive mode.

Silicomolybdic Assay. The concentration of monomeric orthosilicic acid was quantified via the complexation of silicic acid with ammonium molybdate according to an established protocol. ${ }^{35} \mathrm{Si}_{\mathrm{aq}}$ containing salt solutions were prepared in Milli- $Q$ water filtered twice through activated carbon to remove any potential interfering ions. ${ }^{36} \mathrm{To}$ $1.25 \mathrm{ml}$ sample, $50 \mu \mathrm{L}$ of $100 \mathrm{mg} / \mathrm{mL}$ ammonium molybdate solution was added and acidified with $50 \mu \mathrm{L}$ of $1.5 \mathrm{M} \mathrm{H}_{2} \mathrm{SO}_{4}$ (pH 3). After 5 min stirring followed by $5 \mathrm{~min}$ settling time, the adsorption of the yellow $\beta$ complex was measured at $\lambda=400 \mathrm{~nm}$.

\section{RESULTS AND DISCUSSION}

Characterization of the lonic Strength Dependent Coating Deposition of Silicate-TA Networks. The deposition of TA coatings depended on the concentration of $\mathrm{NaCl}$ (Figure 1A). The continuous increase of the coating thickness of silicate-TA networks (Figure S3) with increasing ionic strength at $\mathrm{pH} 8$ reached a maximum layer thickness in the presence of $700 \mathrm{mM} \mathrm{NaCl}$. At a NaCl concentration $c_{\mathrm{NaCl}}<300$ $\mathrm{mM}$, the QCM-D data indicated only the formation of a monolayer. At $c_{\mathrm{NaCl}}=300 \mathrm{mM}$, a continuous deposition process was possible, which increased in efficiency between $400-600$ $\mathrm{mM} \mathrm{NaCl}$. Above $600 \mathrm{mM} \mathrm{NaCl}$ we observed a cloudy solution, which was accompanied by a constant frequency and dissipation drift. Since the control experiment without $\mathrm{Si}_{\mathrm{aq}}$ behaved similarly, we associate this effect with the interaction between $\mathrm{TA}$ and $\mathrm{NaCl}$, resulting in limited TA deposition. As the $\mathrm{NaCl}$ concentration was further increased, more TA precipitated. Thus, unlike TA- $\mathrm{Fe}^{3+}$ networks, silicate-TA coatings did not benefit from $\mathrm{NaCl}$ concentrations beyond $600 \mathrm{mM}^{23}$ The formation of TA aggregates in solution, which lowered the coating efficiency by reducing the amount of free reactive molecules, can be related to the described increase in the roughness of TA- $\mathrm{Fe}^{3+}$ network structures. This effect has been associated with cluster formation of TA molecules enabled by the charge screening effect of $\mathrm{Na}^{+}$ions. ${ }^{23}$

Coating Formation under Substitution of $\mathrm{NaCl}$ with $\mathrm{KCl}$ and $\mathrm{LiCl}$. Upon exchanging $\mathrm{NaCl}$ with $\mathrm{KCl}$ and $\mathrm{LiCl}$, we observed that the deposition of TA layers was negatively affected (Figure 1B). The coating process in $\mathrm{NaCl}$ showed three phases in $\Delta F / \Delta D$ plots (Figure S4) as reported before ${ }^{21}$ and the TA layer reached a thickness of $140 \pm 14 \mathrm{~nm}$ after $4 \mathrm{~h}$. This correlates to a thickness of about $100 \mathrm{~nm}$ in dry state taken into account the hydration of the layer. ${ }^{17}$ The $\mathrm{K}^{+}$based solutions turned turbid immediately upon mixing (see the SI video). This behavior was observed in a $\mathrm{pH}$ range between $\mathrm{pH} 6.0$ and 9.0 and led to a significant loss of coating efficiency, resulting in a thickness of only $18 \pm 6 \mathrm{~nm}$ after $4 \mathrm{~h}$. Above $\mathrm{pH} 9, \mathrm{KCl}$ led to the formation of TA coatings. However, $\mathrm{NaCl}$ did not result in a coating formation (Figure S5). In comparison, $\mathrm{LiCl}$ inhibited the coating formation and delayed the polymerization process substantially as the solutions were not turning turbid during the first $4 \mathrm{~h}$. As a result, a layer thickness of only $3.1 \pm 0.3 \mathrm{~nm}$ was obtained. Neither adjusting the $\mathrm{pH}$ in the range $\mathrm{pH} 6-11$, nor lowering the $\mathrm{LiCl}$ concentration to $50 \mathrm{mM}$ resulted in a successful deposition of TA beyond a monolayer. Further, 

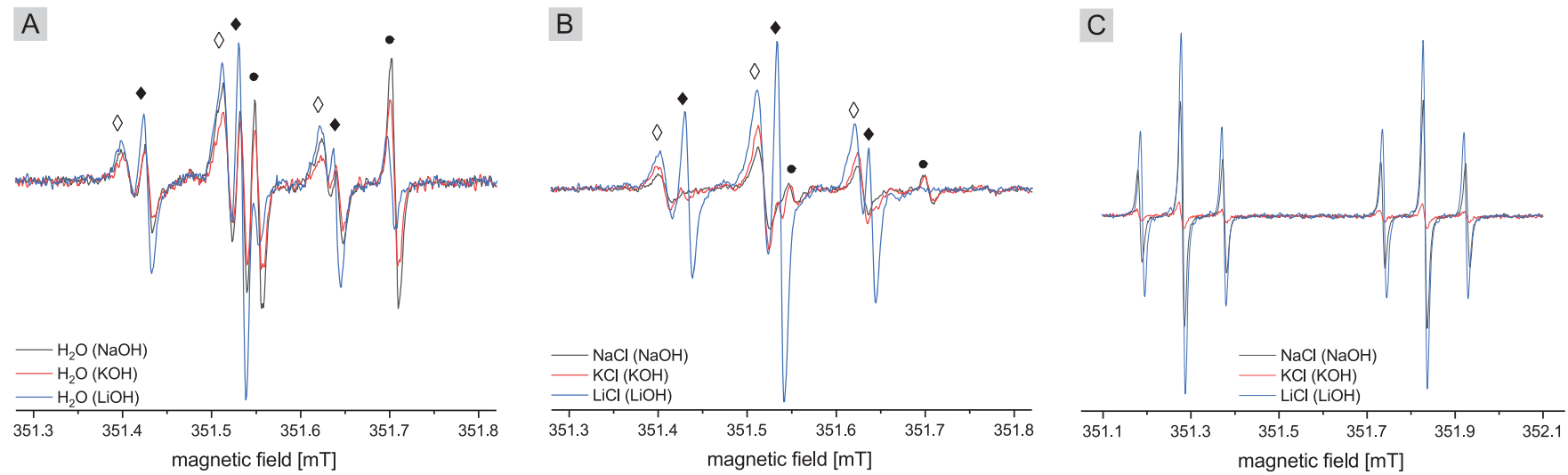

Figure 2. (A) EPR spectrum of $1 \mathrm{mg} / \mathrm{mL}$ TA dissolved in water and (B) $600 \mathrm{mM}$ of either $\mathrm{NaCl}, \mathrm{KCl}$, or LiCl. All solutions were adjusted to pH 11 . (C) EPR spectrum of $1 \mathrm{mg} / \mathrm{mL}$ PG dissolved in $600 \mathrm{mM}$ of either $\mathrm{NaCl}, \mathrm{KCl}$, or $\mathrm{LiCl}$ at $\mathrm{pH} 11$.

increasing the concentration of $\mathrm{Si}_{\mathrm{aq}}$ to $1 \mathrm{mM}$ led only to a slow deposition of TA reaching a layer thickness of $17.0 \pm 0.3 \mathrm{~nm}$ after $4 \mathrm{~h}$ (Figure S6). Higher concentrations of $\mathrm{Si}_{\mathrm{aq}}$ at $\mathrm{pH} 7.8$ were not considered since $\mathrm{Si}_{\mathrm{aq}}$ condensation caused a drifting QCM-D signal (Figure S7).

Although we have shown that silicate-phenolic networks did not form in the presence of $\mathrm{KCl}$ and $\mathrm{LiCl}, \mathrm{Fe}^{+3}$ based metalphenolic films can be assembled in the presence of both salts. ${ }^{24}$ We suspect that the continuous built-up of silicate-TA networks behaved differently compared to $\mathrm{Fe}^{3+}$ based structures due to the interaction of TA and $\mathrm{Si}_{\mathrm{aq}}$. We hypothesize that the assembly of MPN films is mainly facilitated by the strong interaction between vicinal diol groups and $\mathrm{Fe}^{3+}$ compared to possibly weaker interactions of TA with silicic acid. ${ }^{37}$ Contrary to the deposition of silicate-TA layers, PG coatings were successfully formed in all tested salt conditions (Figure S8). While the PG layer reached a higher thickness in the presence of $\mathrm{KCl}$, some larger particles were formed after $12 \mathrm{~h}$ deposition time. This was also represented in QCM-D data showing splitting overtones. Opposed to the TA coating formation, the PG deposition was positively affected by $\mathrm{LiCl}$ and showed higher deposition rates than in $\mathrm{NaCl}$.

The increased coating deposition of $\mathrm{PG}$ in $\mathrm{LiCl}$ solution supports our expectation that the different cations affect the formation of silicate-TA networks. To estimate the strength of cation- $\pi$ complexes, the adhesion force between TA coated surfaces in the presence of salts was determined. Compared to $\mathrm{NaCl}$ and $\mathrm{LiCl}, \mathrm{KCl}$ showed a significantly higher adhesion force between the surfaces (Figure 1C). Cation- $\pi$ interactions are known to follow the stability order $\mathrm{Li}^{+}>\mathrm{Na}^{+}>\mathrm{K}^{+}$in the gas phase, ${ }^{38}$ whereas the order changes in aqueous phase to $\mathrm{K}^{+}>$ $\mathrm{Na}^{+}, \mathrm{Li}^{+}$due to a reduction of the desolvation penalty of the larger $\mathrm{K}^{+}$ion. ${ }^{25,27}$ Indeed, the high affinity of $\mathrm{K}^{+}$ions towards phenolic groups allows $\mathrm{K}^{+}$to replace $\mathrm{Na}^{+}$in polydopamine assemblies and to participate in competitive binding between other cations and aromatic compounds. ${ }^{11,26,27}$ The high interaction potential of $\mathrm{K}^{+}$causes the increased retraction force (Figure 1C) and is also likely to induce the precipitation of $\mathrm{TA}$ in $\mathrm{KCl}$ solution near neutral $\mathrm{pH}$. Thus, $\mathrm{KCl}$ is not well suited for our previously determined coating conditions, in which the layer thickness was increased. ${ }^{17}$

Intermolecular Interaction of TA in the Presence of Different Salts. The difference between the coating formation of TA and PG and the low interaction potential of TA with $\mathrm{Li}^{+}$ raised the question of whether electrostatic interactions sufficiently explain the suppressed coating formation of TA in the presence of $\mathrm{LiCl}$. Preventing the formation of TA coatings by $\mathrm{LiCl}$ could originate from two options: (i) interaction of $\mathrm{Li}^{+}$with TA or (ii) interaction of $\mathrm{Li}^{+}$with $\mathrm{Si}_{\text {aq }}$. It is known that $\mathrm{Li}^{+}$is tightly coordinating $\mathrm{H}_{2} \mathrm{O}$, which may alter the TA hydration shell. ${ }^{39}$ Further, the potential binding to TA hydroxyl reaction sites $^{23}$ and the high stability of ionic $\left(\mathrm{O}^{-} \cdots \mathrm{Li}^{+}\right)$complexes may cause irreversible $\mathrm{Li}^{+}$complexes with phenolic structures. ${ }^{40,41}$ This effect is for example encountered in lithiation of the solidstate interface in energy storage materials. ${ }^{42}$ Regarding interactions between $\mathrm{Li}^{+}$and $\mathrm{Si}_{\mathrm{aq}}$, an interaction preventing the assembly of silicate-TA networks may also be plausible, but evidence of any reactions under the conditions of this study were not found in literature. Therefore, we continued to evaluate whether the different salts have an effect on the reaction chemistry during the layer formation. Since the polyphenol chemistry is largely driven by their oxidation, we studied the formation of polyphenolic radicals to check whether these reaction intermediates are influenced by alkali metal salts.

Polyphenolic Radical Formation. In contrast to the $\mathrm{pH}$ used to obtain coatings, the $\mathrm{pH}$ had to be slightly increased for a reasonable EPR signal. While radicals could be observed at $\mathrm{pH} 9$, the alkalinity of the solutions was further increased to $\mathrm{pH} 11$ for kinetic and quantitative measurements. At this $\mathrm{pH}$, TA presented two main radical triplets $(\diamond, \diamond)$ with 1:2:1 hyperfine splitting intensities and an additional radical doublet $(\mathbf{O})$ with 1:1 hyperfine splitting (Figure 2A). By fitting radical models to the experimental data (Figure S9 and S10), we obtained the proton splitting constants $\left(a^{\mathrm{H}}\right)$, line widths $(\mathrm{LW})$, and g-values of TA radicals (Table 2). Galloyl radicals typically form via a sequential proton loss electron transfer (SPLET) mechanism with the $4 \mathrm{O}^{\bullet}$ being the most stable radical (Scheme 1). ${ }^{43,44}$ In agreement with this structure, the hyperfine splitting of R1 ( and $\mathrm{R} 2(\diamond)$ radicals is caused by the two equivalent protons in

Table 2. Parameters of TA and PG Radical Species

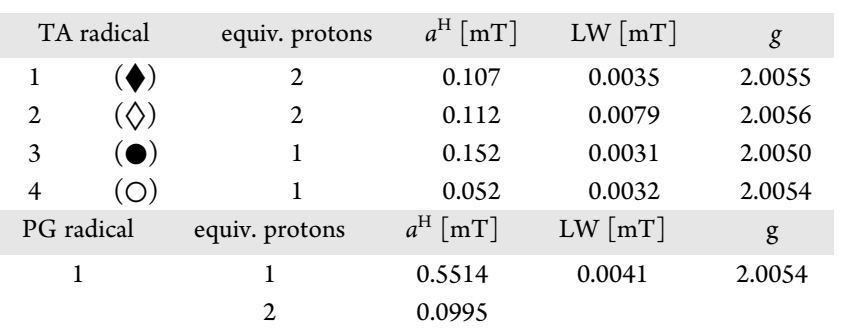


Scheme 1. Scheme of Gallic Acid (GA), Tannic Acid (TA), Pyrogallol (PG), and Ellagic Acid (EA) Radicals with Equivalent Protons Marked in the Same Color<smiles>O=C([O-])c1ccc([O-])c([O-])c1[O-]</smiles>

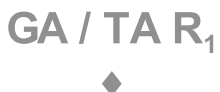<smiles>O=c1oc2c([O-])c(O)cc3c(=O)oc4c([O-])c([O-])cc1c4c23</smiles>

EA R $R_{1} / \mathrm{TA} \mathrm{R}_{4}$<smiles>[R]OC(=O)c1ccc([O-])c([O-])c1[O-]</smiles><smiles>[R]C1C2CC1C21CC1</smiles><smiles>[CH]1C=C1</smiles><smiles>[R]C1[C@H]2CC[C@H]12</smiles>
$\bullet$<smiles>O=C([O-])c1ccc([O-])c(Oc2c([O-])c([O-])c([O-])c([O-])c2[O-])c1[O-]</smiles>

GA $\mathbf{R}_{2}$ the galloyl group. The - -radical displayed HFC constant $a^{\mathrm{H}}=$ $0.107 \mathrm{mT}$ and a LW equal to gallic acid (GA), the structural subunit of TA (Figure S11). ${ }^{45}$ In comparison, the $\diamond$ radical has a broader LW and slightly higher $a^{\mathrm{H}}$.

The occurrence of two different radicals may be explained by differences in spin density or spin relaxation times in the outer galloyl group compared to the inner group. It has been proposed that both groups are chemically not equivalent with the inner galloyl groups being more prone to oxidation. ${ }^{46}$ However, since we have found free GA in the commercial TA (Figure S12), and para-substitution in TA increases the coupling constant, ${ }^{47}$ it is more likely that the R1 ( $)$ radical corresponds to free GA radicals. Under this assumption, R2 $(\diamond)$ represents the radical of a galloyl ester group, which we have proven by comparing TA with penta-galloyl glucose (PGG) radicals (Figure S13). Thus, our results agree with previous studies determining the HFC constant of PGG radicals and gallate-ester radicals. ${ }^{31,32}$ In addition, after purification of the commercial TA, we observed a spectrum with one $\diamond$-radical triplet (Figure S14). Once the purified TA was subjected to higher $\mathrm{pH}$, the second -radical emerged in the spectrum indicating hydrolysis of the galloyl groups from TA, generating free GA.

R3 (O) however represents an unknown radical structure coupling with only one proton. Although phenolic molecules may form $\mathrm{C}-\mathrm{C}$ bonds at $\mathrm{C} 2$ or $\mathrm{C} 6$ position, the coupling constant is unreasonably high and not comparable to $\mathrm{C}-\mathrm{C}$ coupling observed in ellagitannins (Figure S15). ${ }^{48}$ The low HFC constant $a^{\mathrm{H}}=0.05 \mathrm{mT}$ in ellagic acid indicates a low electron spin density at the meta position to the radical electron as indicated in Scheme 1. This stands in contrast to reports suggesting that this EA radical position is thermodynamically not the most stable species. ${ }^{49}$ Further, the higher $g$-value of the O-radical compared to $\diamond$ - and $\rangle$-radicals may suggest the substitution of a phenolic ring proton with an electron donating group. ${ }^{50}$ Recent quantum chemical studies have shown that hydrogen bonding affects the radicalization mechanism for various phenolic structures. ${ }^{51}$ Yet these models need further experimental evidence to deduct the molecular structure of the O-radical.

Altered Radical Formation in the Presence of Alkali Metal Salts. EPR spectra of saline TA solutions showed a significant salt dependent difference in the intensity of both $\diamond$ and - -radical species and the absence of - -radicals in the EPR spectra of $\mathrm{TA}$ solutions containing $\mathrm{LiCl}$ (Figure 2B). In the presence of $\mathrm{NaCl}$ and $\mathrm{KCl}$, commercial TA preferably yielded a $\checkmark$-radical, whereas $\mathrm{LiCl}$ facilitated the formation of the $\checkmark$-radical. While radical parameters of both $\rangle$ - and $\downarrow$-radicals in $\mathrm{NaCl}$ and $\mathrm{KCl}$ solution did not differ from their corresponding signals without salt, $\mathrm{LiCl}$ appeared to slightly reduce the HFC constant compared to solutions without salt. This can be explained by influences in charge densities caused by the cation. ${ }^{34,41}$ All salts produced lower intensities for $\boldsymbol{\text { - and }}$ $\checkmark$-radicals (Figure S16). At $\mathrm{pH} 9$, this effect was however canceled by $\mathrm{Si}_{\mathrm{aq}}$ for $\mathrm{NaCl}$ and $\mathrm{LiCl}$ (Figure S16), which suggests a radical stabilizing effect similar to $\mathrm{Zn}^{2+}$. 33,52

We conducted further studies investigating whether the -radical is a specific form of oxidation product by inducing the radical formation chemically with periodic acid and sodium persulfate. ${ }^{53,54}$ However, neither oxidant resulted in a significant change in the observed TA radical species (Figure S17). Further, no radicals could be detected in the sole presence of the oxidants. Since the oxidation in alkaline condition is strongly dependent on the oxygen update, ${ }^{15}$ we next investigated the radical formation under varying $\mathrm{O}_{2}$ uptake. We observed a new radical $(\bigcirc)$ displaying a doublet structure with $a^{\mathrm{H}}=0.052 \mathrm{mT}$ in vigorously shaken solutions (Figure S18). This species was observed directly at $t=0 \mathrm{~min}$ and appeared more stable than the other radical species. It is likely a reaction product of the oxidative coupling of $\mathrm{GA},{ }^{55}$ since the similarity to EA radicals is striking (Figure S15).

To compare our observations for TA to the deposition of PG coatings, we further studied PG radicals (Figure 2C). At $\mathrm{pH} 11$, 
the EPR spectrum presented a doublet composed of 1:2:1 triplets with $a^{\mathrm{H}}=0.551$ and $0.099 \mathrm{mT}$, respectively (Table 2). This pattern originated from the two chemically different protons of PG (Scheme 1), with the para proton exhibiting the larger HFC constant. Both in $\mathrm{LiCl}$ and $\mathrm{NaCl}, \mathrm{PG}$ displayed similar EPR signals at $\mathrm{pH} 11 . \mathrm{KCl}$ however led to a reduced intensity, which stands in contrast to the observed coating formation. The same result was also observed in solutions without the respective salt.

In conclusion, the structure of the -radical remained unexplained and we suggest it is a form of contamination in commercial TA since it did not appear in the purified TA spectra. However, we have shown that $\mathrm{NaCl}$ facilitated the formation of the TA radical, whereas in the presence of $\mathrm{Li}^{+}, \mathrm{GA}$ radicals were observed. The formation of GA could be the reason for the reduced ability to form coatings since GA cannot be continuously deposited on surfaces. ${ }^{22}$ The lower molecular weight GA potentially reacts faster with $\mathrm{Si}_{\mathrm{aq}}$ and blocks the formation of TA coatings. Additionally, PG only showed one type of radical with a salt dependent intensity. This may explain why PG coatings were formed regardless of the type of salt.

pH Dependent TA Radical Distribution. After observing a salt dependent $\mathrm{TA}$ radical distribution, we investigated whether different salts have an effect on TA radicals at varying $\mathrm{pH}$. With increasing $\mathrm{pH}$, an increase in signal intensity (Figure S19) was accompanied by a change in the ratio of the two main

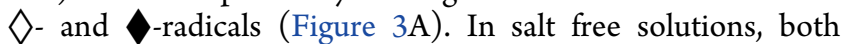
radicals were almost equally distributed at $\mathrm{pH} 11$ and 12 . Once the $\mathrm{pH}$ is further raised to $\mathrm{pH} 13, \mathrm{~K}^{+}$based solutions showed higher contents of the $\diamond$-radical, while in $\mathrm{NaOH}$ the ratio is shifted more to the -radical. Solutions adjusted with $\mathrm{LiOH}$ resulted in a -radical dominated spectrum. Upon including salts, the $\mathrm{K}^{+}$and $\mathrm{Na}^{+}$based spectra indicated higher content of $\checkmark$-radicals throughout the whole $\mathrm{pH}$ range (Figure $3 \mathrm{~B}$ ). In contrast, $\mathrm{LiCl}$ increased the ratio of the -radical even more compared to $\mathrm{LiOH}$ solutions. This corroborates our previous result with purified TA (Figure S14) showing that with increasing $\mathrm{pH}$ TA hydrolyses and breaks down to form GA subunits and that this process is reduced in $\mathrm{NaCl}$ and $\mathrm{KCl}$ but accelerated in $\mathrm{LiCl}$ solution. The HFC parameters of $\diamond$ - and $\checkmark$-radicals further showed a decrease in $\mathrm{LiCl}$ solution with increased LiOH concentration to $a^{\mathrm{H}}=0.102 \mathrm{mT}$ and $a^{\mathrm{H}}=0.108$ $\mathrm{mT}$ respectively (Table S3). Further, the decreasing coupling constant indicates strong $\mathrm{Li}$-coordination to the phenol group affecting its electron distribution. Similar ion specific interactions have been observed in anhydrous environment. ${ }^{56}$ These results support our initial observation that $\mathrm{LiCl}$ has a distinct role in the formation of GA radicals. Further, the trend allows us to extrapolate to $\mathrm{pH}$ level closer to the coating conditions for which we expect similar behavior.

Time Dependent TA Radical Stability. Radicals are shortlived intermediary structures and key structures in oxidative reactions. ${ }^{47}$ Hence, we investigated the decay of the radicals over time. TA radicals at $\mathrm{pH} 12$ were stable for more than $3.5 \mathrm{~h}$ in $\mathrm{NaOH}, \mathrm{KOH}$, and $\mathrm{LiOH}$ solution (Figure $3 \mathrm{C}-\mathrm{E}$ ). However, the presence of the respective salts compromised TA radical lifetime, as the signals decayed before $3.5 \mathrm{~h}$. In the course of the decay, the intensity of the $\diamond$ radical continuously decreased and diminished earlier than the - -radical. This may indicate a transformation of the $\diamond$ radical to the $\nabla$-radical and a subsequent radical termination. Thus, this time dependent signal reduction also supports the suspected hydrolysis reaction. Coincidentally this timespan correlates with the kinetically
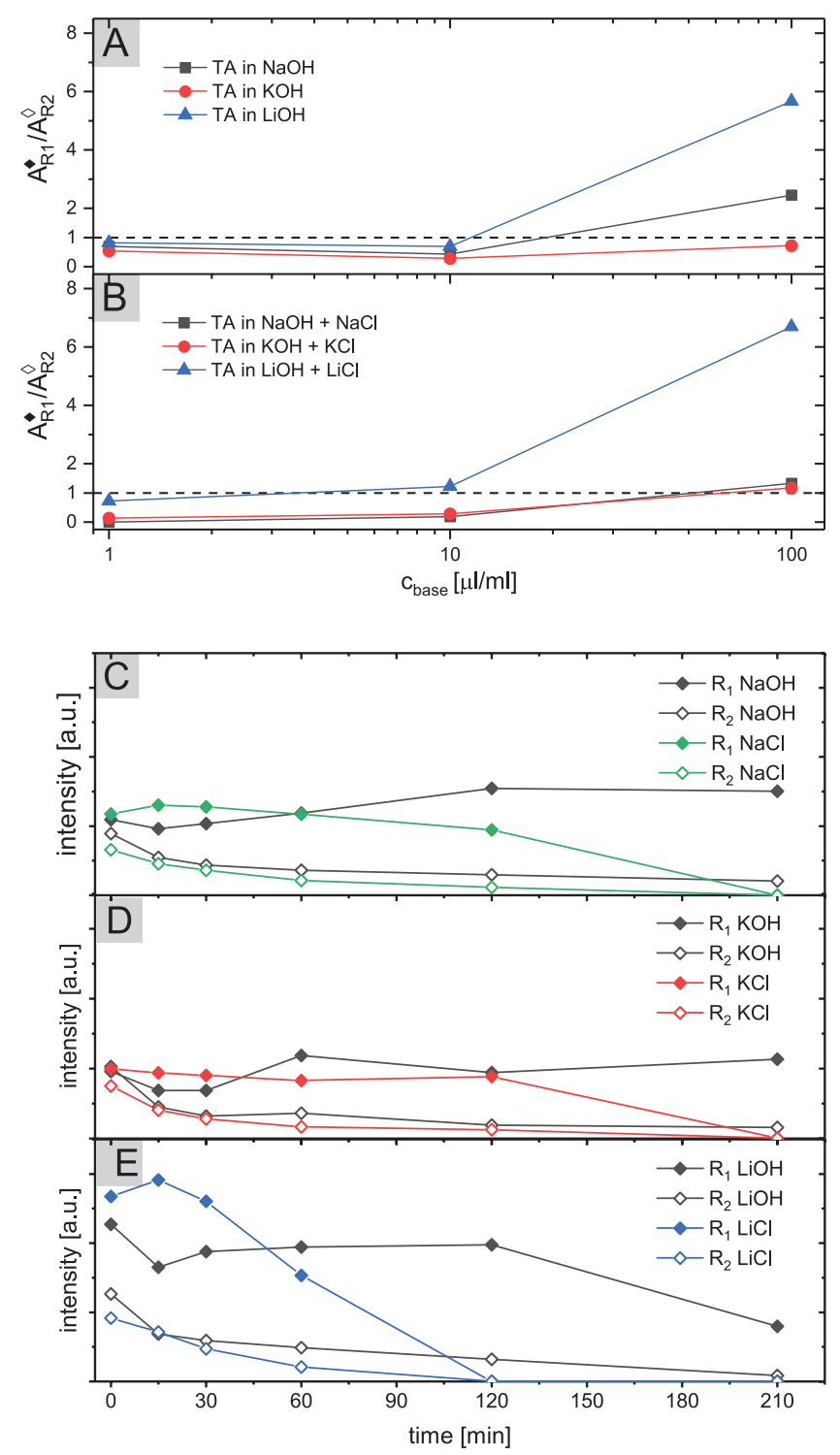

Figure 3. (A) Ratios of modeled peak areas of TA radical 1 ( radical $2(\diamond)$ in water and $(B)$ salt containing solutions. (C) Time dependent radical decay of TA dissolved in $\mathrm{Na}^{+}$, (D) $\mathrm{K}^{+}$, and (E) $\mathrm{Li}^{+}$ containing solutions at $\mathrm{pH} 12$.

fastest period of the coating formation suggesting that radicals could play a key role in this process. ${ }^{17,21}$

Spectroscopic Structure Analysis. A clear limitation of the EPR measurements is however the raised $\mathrm{pH}$ compared to the coating condition. TA coatings could not be obtained in $\mathrm{NaCl}$ solution above $\mathrm{pH} 9$ (Figure S5). Only in $\mathrm{KCl}$ it was still possible, presumably due to retaining of the TA radical structure. However, we expect that reactions occur already at lower $\mathrm{pH}$, which only get accelerated in alkaline $\mathrm{pH}$. To support our EPR results showing that $\mathrm{Li}^{+}$ions alter the electronic structure of polyphenols also at coating conditions, we studied the UV-vis spectra of TA for different $\mathrm{pH}$ levels.

The absorption peak of pristine TA at $275 \mathrm{~nm}$ changed upon $\mathrm{pH}$ induced oxidation and resulted in two peaks appearing at 234 and $324 \mathrm{~nm}$ due to deprotonation (Figure 4A). ${ }^{57}$ These decayed above $\mathrm{pH} \mathrm{11}$, indicating that the molecules have lost their initial structure (Figure S20). While we did not observe significant differences in TA solutions adjusted with any of the bases $\mathrm{NaOH}, \mathrm{KOH}$, or $\mathrm{LiOH}$, the addition of salts resulted in 

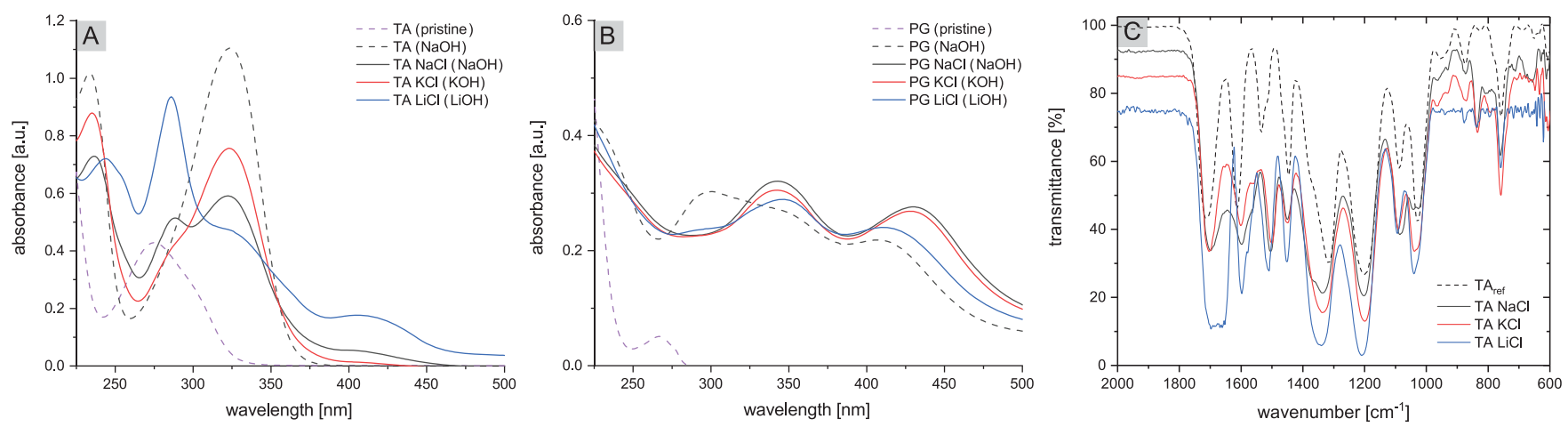

Figure 4. (A) UV-vis spectra of TA and (B) PG at concentrations of $0.01 \mathrm{mg} / \mathrm{mL}$. Solutions were supplemented with $600 \mathrm{mM} \mathrm{NaCl}, \mathrm{KCl}$, or LiCl and adjusted to $\mathrm{pH}$ 7. For representation, the respective polyphenolic solution without salt is added in dashed lines. (C) FTIR spectra of TA supplemented with $600 \mathrm{mM} \mathrm{NaCl}, \mathrm{KCl}$, or $\mathrm{LiCl}$ and adjusted to $\mathrm{pH} 8$.

the appearance of a peak at $290 \mathrm{~nm}$ at $\mathrm{pH} 7$. In solutions containing $\mathrm{NaCl}$, the peak at $290 \mathrm{~nm}$ was distinct while in $\mathrm{KCl}$ it existed only as a shoulder of the $324 \mathrm{~nm}$ peak and in $\mathrm{LiCl}$ it was the main peak of the spectrum. These peaks may be an indication for the formation of GA and EA, which show peaks around $290 \mathrm{~nm}$ (Figure S21). ${ }^{58}$ These results confirm our EPR and LC-MS results and point out that $\mathrm{LiCl}$ leads to hydrolysis of TA.

We further analyzed the spectra of PG with the hypothesis that we observe less distinct differences between the added salts. While PG dissolved in water showed a peak at $268 \mathrm{~nm}$, three peaks merged at 300,335 , and $410 \mathrm{~nm}$ after increasing the $\mathrm{pH}$ with $\mathrm{NaOH}, \mathrm{KOH}$, or $\mathrm{LiOH}$ (Figure S22). Adding salts to PG solutions at $\mathrm{pH} 7$ reduced the peak at $300 \mathrm{~nm}$ resulting in a double peak at 345 and $430 \mathrm{~nm}$ (Figure 4B). The lack of significant differences in the PG spectra confirm the hypothesis and support the salt independent coating formation of PG.

Since we had evidence for the creation of GA and EA, we investigated whether we can determine changes in the chemical structure of TA solutions by FTIR. The presence of salts resulted in minor peak shifts and peak broadening of TA spectra at $\mathrm{pH} 8$ compared to pristine TA (Figure 4C). However, the peak broadening was primarily induced by the change in $\mathrm{pH}$ (Figure S23). These peak shifts in the range of $2-5 \mathrm{~cm}^{-1}$ have been observed for $\mathrm{K}$ - and Li-phenolates ${ }^{59}$ as well as for Fe-TA network structures. ${ }^{60}$ The most dominant differences are (i) the shift of the $\mathrm{C}=\mathrm{C}$ stretching vibration from 1534 to $1505 \mathrm{~cm}^{-1}$, (ii) the broadening and shift of phenolic $\mathrm{C}-\mathrm{O}$ and $\mathrm{C}-\mathrm{H}$ bending vibrations from 1316 to $1340 \mathrm{~cm}^{-1}$ (Table S4), and (iii) the shift of the $\mathrm{C}-\mathrm{H}$ bending vibration from 1030 to $1040 \mathrm{~cm}^{-1}$ in alkaline conditions. These differences correlate to EA and GA spectra (Figure S23D) and may thus indicate the formation of EA and GA upon oxidation of TA. The addition of $100 \mu \mathrm{M} \mathrm{Si}_{\mathrm{aq}}$ in $\mathrm{Li}^{+}$and $\mathrm{K}^{+}$systems did not lead to changes in the spectra. However, $\mathrm{Na}^{+}$systems with $\mathrm{Si}_{\mathrm{aq}}$ showed variations in the peakto-peak intensities for absorption bands at $1598 \mathrm{~cm}^{-1}, 1504$ $\mathrm{cm}^{-1}, 1087 \mathrm{~cm}^{-1}$ and $1026 \mathrm{~cm}^{-1}$. Although FTIR results are not suitable for an absolute structure determination due to the high similarity of TA, GA, and EA spectra, the obtained results indicate a plausible mixture of the compounds. Moreover, TA precipitate $\left(\mathrm{TA}_{\mathrm{P}}\right)$, we observed during the coating formation, showed typical oxidation induced peak shifts for both $\mathrm{NaCl}$ and $\mathrm{LiCl}$ containing solutions (Figure S24), ${ }^{22}$ whereas $\mathrm{KCl}$ captured TA in its non-oxidized form.

Additionally, we conducted NMR experiments to check for changes caused by the interaction between $\mathrm{TA}$ and $\mathrm{Na}^{+}, \mathrm{K}^{+}$, or
$\mathrm{Li}^{+}$. The ${ }^{13} \mathrm{C}$ NMR of TA showed a typical spectrum and no apparent changes in the presence of salts and $\mathrm{Si}_{\mathrm{ag}}$ were observed (Figure S25). Similar to LC-MS (Figure S12), ${ }^{13} \mathrm{C}$ NMR of TA solutions showed the presence of free gallic acid. A correlation with emerging $\mathrm{C}-\mathrm{O}-\mathrm{Si}$ bonds could not be obtained to study the interaction of TA and $\mathrm{Si}_{\mathrm{aq}}$ as described by solid-state $\mathrm{NMR}{ }^{17}$ Precipitation occurring during the course of the measurement likely excluded the cross-linked TA molecules from being NMR active.

Interaction of $\mathrm{Na}^{+}, \mathrm{K}^{+}$, and $\mathrm{Li}^{+}$with $\mathrm{Si}_{\text {aq. }}$. We investigated the potential of salts to interact with $\mathrm{Si}_{\mathrm{aq}}$ inhibiting the formation of silicate-phenolic networks by blocking silicic acid. ${ }^{29} \mathrm{Si} \mathrm{NMR}$ experiments of $0.1 \mathrm{M} \mathrm{Si}_{\mathrm{aq}}$ showed a major peak for silicic acid $\left(\mathrm{Q}^{0}\right)$ followed by minor peaks of $\mathrm{Si}$ polycondensates with $\mathrm{Q}^{1}$ and $\mathrm{Q}^{2}$ states (Figure S26). ${ }^{61}$ Only minor shifts of 0.2 and 0.3 ppm occurred in the solutions containing $600 \mathrm{mM} \mathrm{NaCl}$ or $\mathrm{LiCl}$, respectively, which can be explained by ion-pairing. ${ }^{62}$ However, more elaborate experiments have previously shown irreversible complexation of silicate anions with $\mathrm{Li}^{+} .63$ We could not determine these interactions by NMR and our sole observation that $\mathrm{Si}_{\mathrm{aq}}$ interacts with $\mathrm{LiCl}$ is based on QCM-D data that showed a significantly reduced $\mathrm{Si}_{\mathrm{aq}}$ condensation in $\mathrm{LiCl}$ solution (Figure S7D).

Finally, we evaluated the amount of free silicic acid in solutions containing $\mathrm{NaCl}, \mathrm{KCl}$, and $\mathrm{LiCl}$ by a silico-molybdic assay. The assay resulted in an equal amount of free $\mathrm{Si}_{\mathrm{aq}}$ irrespective of the added salts. The linear correlation between the absorbance of the silico-molybdic complex was maintained until the capacity of the assay was reached well beyond the concentration of $\mathrm{Si}_{\mathrm{aq}}$ used to obtain TA coatings (Figure S27). ${ }^{35}$ Although we did not observe a reduction of free silicic acid we take into account that the acidic $\mathrm{pH}$ may shift the dissociation of the weak silicic acid $\left(\mathrm{p} K_{\mathrm{A}}=9.8\right)$ towards neutral charge, thus limiting its interaction with cations and not representing reactions at the coating condition.

\section{CONCLUSION}

We have taken a closer look at the effects of different salts and their concentration on the silica $\left(\mathrm{Si}_{\mathrm{aq}}\right)$ mediated coating formation of tannic acid (TA). Our results revealed that 600 $\mathrm{mM} \mathrm{NaCl}$ is required to effectively form silicate-phenolic networks. Substitution with $\mathrm{KCl}$ resulted in strong interaction with TA leading to precipitation near neutral $\mathrm{pH}$, whereas $\mathrm{LiCl}$ prevented any deposition of TA coatings beyond a monolayer.

Using EPR, we obtained insight into the salt dependent radical formation during the oxidation of TA. While $\mathrm{NaCl}$ 
promoted the formation of $\mathrm{TA}$ radicals, $\mathrm{LiCl}$ resulted in the formation of GA radicals. $\mathrm{LiCl}$ is likely contributing to hydrolytic cleavage of the galloyl ester bonds of TA and thereby inhibiting the formation of silicate-TA networks. In contrast, pyrogallol (PG) coatings, which do not rely on $\mathrm{Si}_{\mathrm{aq}}$ crosslinking, were independent on the type of alkali metal cation and EPR spectra did not show a salt dependent radical formation. Although EPR experiments were conducted at elevated $\mathrm{pH}$, supporting spectroscopic experiments corroborated that $\mathrm{LiCl}$ results in hydrolysis of TA also under coating conditions. Further, we obtained indications that $\mathrm{LiCl}$ interacts with $\mathrm{Si}_{\mathrm{aq}}$, preventing the formation of silicate-TA networks.

In summary, we highlight that charge screening may not be the only important interaction of alkali metal salts in the chemistry of silicate-phenolic networks. Depending on the coating mechanism, the specific interactions between polyphenols and cations must be taken into consideration to obtain desired reaction conditions in biologically relevant environments. Our EPR data lays the fundament for further quantum chemical investigations of phenolic radicals. This may find application in further investigations into the chemistry of polyphenols, e.g., whether TA radicals are a prerequisite to form silicate-phenolic networks.

\section{ASSOCIATED CONTENT}

\section{SI Supporting Information}

The Supporting Information is available free of charge at https://pubs.acs.org/doi/10.1021/acsami.0c16946.

Details on EPR modeling, QCM-D raw data, and supplementary UV-vis, EPR, and FTIR spectra (PDF) Turbidity of the $\mathrm{K}^{+}$based solutions immediately upon mixing (MP4)

\section{AUTHOR INFORMATION}

\section{Corresponding Author}

Hanna Tiainen - Department of Biomaterials, Institute of Clinical Dentistry, University of Oslo, Oslo 0317, Norway; 다이.org/0000-0003-2757-6213; Email: hanna.tiainen@ odont.uio.no

\section{Authors}

Florian Weber - Department of Biomaterials, Institute of Clinical Dentistry, University of Oslo, Oslo 0317, Norway

Einar Sagstuen - Department of Physics, University of Oslo, Oslo 0317, Norway; 이이.org/0000-0003-4261-1398

Qi-Zhi Zhong - Centre of Excellence in Convergent Bio-Nano Science and Technology, Department of Chemical Engineering, The University of Melbourne, Melbourne 3010, Australia

Tian Zheng - Materials Characterisation and Fabrication Platform, Department of Chemical Engineering, The University of Melbourne, Melbourne 3010, Australia

Complete contact information is available at: https://pubs.acs.org/10.1021/acsami.0c16946

\section{Author Contributions}

The manuscript was written by contributions of all authors. All authors have given approval to the final version of the manuscript.

\section{Funding}

This work was financially supported by the Research Council of Norway (Grant No. 302590), UiO Life Science, and through the Norwegian NMR Package in 1994 for the Department of
Chemistry and the Faculty of Mathematics and Natural Sciences at the University of Oslo.

\section{Notes}

The authors declare no competing financial interest.

\section{ACKNOWLEDGMENTS}

We kindly acknowledge the help from Frode Rise (University of Oslo) with NMR measurements and related discussions, Hellen Collins (University of Adelaide), Jelle Lahnstein (University of Adelaide), and Helle Wangensteen (University of Oslo) for support with LC-MS experiments.

\section{ABBREVIATIONS}

TA, tannic acid; PG, pyrogallol; GA, gallic acid; EA, ellagic acid; PGG, penta-galloyl glucose; $\mathrm{Si}_{\mathrm{aq}}$, silicic acid dissolved in water; MPN, metal-phenolic network; HFC, hyperfine coupling

\section{REFERENCES}

(1) Sileika, T. S.; Barrett, D. G.; Zhang, R.; Lau, K. H. A.; Messersmith, P. B. Colorless Multifunctional Coatings Inspired by Polyphenols Found in Tea, Chocolate, and Wine. Angew. Chem., Int. Ed. 2013, 52 (41), 10766-10770.

(2) Ejima, H.; Richardson, J. J.; Caruso, F. Metal-Phenolic Networks as a Versatile Platform to Engineer Nanomaterials and Biointerfaces. Nano Today 2017, 12, 136-148.

(3) Ryu, J. H.; Messersmith, P. B.; Lee, H. Polydopamine Surface Chemistry: A Decade of Discovery. ACS Appl. Mater. Interfaces 2018, 10 (9), 7523-7540.

(4) Guo, J.; Suma, T.; Richardson, J. J.; Ejima, H. Modular Assembly of Biomaterials Using Polyphenols as Building Blocks. ACS Biomater. Sci. Eng. 2019, 5 (11), 5578-5596.

(5) Lee, H. A.; Ma, Y.; Zhou, F.; Hong, S.; Lee, H. MaterialIndependent Surface Chemistry Beyond Polydopamine Coating. Acc. Chem. Res. 2019, 52 (3), 704-713.

(6) Quideau, S.; Deffieux, D.; Douat-Casassus, C.; Pouységu, L. Plant Polyphenols: Chemical Properties, Biological Activities, and Synthesis. Angew. Chem., Int. Ed. 2011, 50 (3), 586-621.

(7) Chen, Y.; Liu, Q. Oxidant-Induced Plant Phenol Surface Chemistry for Multifunctional Coatings: Mechanism and Potential Applications. J. Membr. Sci. 2019, 570-571, 176-183.

(8) Yang, S.; Xu, Y.; Lin, Q.; Bai, Y.; Zan, X.; Ye, Q. A Bio-Inspired, One-Step but Versatile Coating onto Various Substrates with Strong Antibacterial and Enhanced Osteogenesis. Chem. Commun. 2019, 55 (14), 2058-2061.

(9) Zhao, X.; Zhang, R.; Liu, Y.; He, M.; Su, Y.; Gao, C.; Jiang, Z. Antifouling Membrane Surface Construction: Chemistry Plays a Critical Role. J. Membr. Sci. 2018, 551, 145-171.

(10) Li, X.; Gao, P.; Tan, J.; Xiong, K.; Maitz, M. F.; Pan, C.; Wu, H.; Chen, Y.; Yang, Z.; Huang, N. Assembly of Metal-Phenolic/ Catecholamine Networks for Synergistically Anti-Inflammatory, Antimicrobial, and Anticoagulant Coatings. ACS Appl. Mater. Interfaces 2018, 10 (47), 40844-40853.

(11) Hong, S.; Wang, Y.; Park, S. Y.; Lee, H. Progressive Fuzzy Cation$\Pi$ Assembly of Biological Catecholamines. Sci. Adv. 2018, 4 (9), eaat7457.

(12) Barrett, D. G.; Sileika, T. S.; Messersmith, P. B. Molecular Diversity in Phenolic and Polyphenolic Precursors of Tannin-Inspired Nanocoatings. Chem. Commun. 2014, 50 (55), 7265-7268.

(13) Rahim, M. A.; Ejima, H.; Cho, K. L.; Kempe, K.; Müllner, M.; Best, J. P.; Caruso, F. Coordination-Driven Multistep Assembly of Metal-Polyphenol Films and Capsules. Chem. Mater. 2014, 26 (4), $1645-1653$

(14) Liebscher, J. Chemistry of Polydopamine - Scope, Variation, and Limitation. Eur. J. Org. Chem. 2019, 2019, 4976-4984.

(15) Marklund, S.; Marklund, G. Involvement of the Superoxide Anion Radical in the Autoxidation of Pyrogallol and a Convenient 
Assay for Superoxide Dismutase. Eur. J. Biochem. 1974, 47 (3), 469474.

(16) Zeng, L.; Ma, M.; Li, C.; Luo, L. Stability of Tea Polyphenols Solution with Different Ph at Different Temperatures. Int. J. Food Prop. 2017, 20 (1), 1-18.

(17) Weber, F.; Liao, W.-C.; Barrantes, A.; Edén, M.; Tiainen, H. Silicate-Phenolic Networks: Coordination Mediated Deposition of Bioinspired Tannic Acid Coatings. Chem. - Eur. J. 2019, 25, 98709874.

(18) Saiz-Poseu, J.; Mancebo-Aracil, J.; Nador, F.; Busque, F.; RuizMolina, D. The Chemistry Behind Catechol-Based Adhesion. Angew. Chem., Int. Ed. 2019, 58 (3), 696-714.

(19) Ejima, H.; Richardson, J. J.; Liang, K.; Best, J. P.; van Koeverden, M. P.; Such, G. K.; Cui, J.; Caruso, F. One-Step Assembly of Coordination Complexes for Versatile Film and Particle Engineering. Science 2013, 341 (6142), 154-157.

(20) Slabbert, N. Complexation of Condensed Tannins with Metal Ions. In Plant Polyphenols; Springer: Berlin, 1992; pp 421-436.

(21) Geißler, S.; Barrantes, A.; Tengvall, P.; Messersmith, P. B.; Tiainen, H. Deposition Kinetics of Bioinspired Phenolic Coatings on Titanium Surfaces. Langmuir 2016, 32 (32), 8050-8060.

(22) Weber, F.; Barrantes, A.; Tiainen, H. Silicic Acid Mediated Formation of Tannic Acid Nanocoatings. Langmuir 2019, 35 (9), 3327-3336.

(23) Guo, J.; Richardson, J. J.; Besford, Q. A.; Christofferson, A. J.; Dai, Y.; Ong, C. W.; Tardy, B. L.; Liang, K.; Choi, G. H.; Cui, J.; Yoo, P. J.; Yarovsky, I.; Caruso, F. Influence of Ionic Strength on the Deposition of Metal-Phenolic Networks. Langmuir 2017, 33 (40), 10616-10622.

(24) Park, T.; Kim, W. I.; Kim, B. J.; Lee, H.; Choi, I. S.; Park, J. H.; Cho, W. K. Salt-Induced, Continuous Deposition of Supramolecular Iron(Iii)-Tannic Acid Complex. Langmuir 2018, 34 (41), 1231812323.

(25) Kumpf, R.; Dougherty, D. A Mechanism for Ion Selectivity in Potassium Channels: Computational Studies of Cation-Pi Interactions. Science 1993, 261 (5129), 1708-1710.

(26) Park, S.; Kim, S.; Jho, Y.; Hwang, D. S. Cation-П Interactions and Their Contribution to Mussel Underwater Adhesion Studied Using a Surface Forces Apparatus: A Mini-Review. Langmuir 2019, 35 (48), 16002-16012.

(27) Lu, Q.; Oh, D. X.; Lee, Y.; Jho, Y.; Hwang, D. S.; Zeng, H. Nanomechanics of Cation- $\Pi$ Interactions in Aqueous Solution. Angew. Chem., Int. Ed. 2013, 52 (14), 3944-3948.

(28) Zhang, J.; Xiang, L.; Yan, B.; Zeng, H. Nanomechanics of Anion-П Interaction in Aqueous Solution. J. Am. Chem. Soc. 2020, 142 (4), 1710-1714.

(29) Tóth, I. Y.; Szekeres, M.; Turcu, R.; Sáringer, S.; Illés, E.; Nesztor, D.; Tombácz, E. Mechanism of in Situ Surface Polymerization of Gallic Acid in an Environmental-Inspired Preparation of Carboxylated CoreShell Magnetite Nanoparticles. Langmuir 2014, 30 (51), 1545115461.

(30) Tollin, G.; Steelink, C. Biological Polymers Related to Catechol: Electron Paramagnetic Resonance and Infrared Studies of Melanin, Tannin, Lignin, Humic Acid and Hydroxyquinones. Biochim. Biophys. Acta, Biophys. Incl. Photosynth. 1966, 112 (2), 377-379.

(31) Severino, J. F.; Goodman, B. A.; Kay, C. W. M.; Stolze, K.; Tunega, D.; Reichenauer, T. G.; Pirker, K. F. Free Radicals Generated During Oxidation of Green Tea Polyphenols: Electron Paramagnetic Resonance Spectroscopy Combined with Density Functional Theory Calculations. Free Radical Biol. Med. 2009, 46 (8), 1076-1088.

(32) Bors, W.; Michel, C.; Stettmaier, K. Electron Paramagnetic Resonance Studies of Radical Species of Proanthocyanidins and Gallate Esters. Arch. Biochem. Biophys. 2000, 374 (2), 347-355.

(33) Kalyanaraman, B. Characterization of O-Semiquinone Radicals in Biological Systems. In Methods in Enzymology; Academic Press: New York, 1990; Vol. 186, pp 333-343.

(34) Alegría, A. E.; Sanchez-Cruz, P.; Rivas, L. Alkaline-Earth Cations Enhance Ortho-Quinone-Catalyzed Ascorbate Oxidation. Free Radical Biol. Med. 2004, 37 (10), 1631-1639.
(35) Coradin, T.; Eglin, D.; Livage, J. The Silicomolybdic Acid Spectrophotometric Method and Its Application to Silicate/Biopolymer Interaction Studies. Spectroscopy 2004, 18 (4), 567-576.

(36) Goher, M. E.; Hassan, A. M.; Abdel-Moniem, I. A.; Fahmy, A. H.; Abdo, M. H.; El-sayed, S. M. Removal of Aluminum, Iron and Manganese Ions from Industrial Wastes Using Granular Activated Carbon and Amberlite Ir-120h. Egypt. J. Aquat. Res. 2015, 41 (2), 155164.

(37) Huang, S.-P.; Li, W.; Franz, K. J.; Albright, R. L.; Fish, R. H. Polymer Pendant Ligand Chemistry. 3. A Biomimetic Approach to Selective Metal Ion Removal and Recovery from Aqueous Solution with Polymer-Supported Sulfonated Catechol and Linear Catechol Amide Ligands. Inorg. Chem. 1995, 34 (11), 2813-2819.

(38) Reddy, A. S.; Sastry, G. N. Cation $\left[\mathrm{M}=\mathrm{H}^{+}, \mathrm{Li}^{+}, \mathrm{Na}^{+}, \mathrm{K}^{+}, \mathrm{Ca}^{2+}\right.$, $\mathrm{Mg}^{2+}, \mathrm{Nh}^{4+}$, and $\mathrm{Nme}^{4+}$ Interactions with the Aromatic Motifs of Naturally Occurring Amino Acids: A Theoretical Study. J. Phys. Chem. A 2005, 109 (39), 8893-8903.

(39) Ikeda, T.; Boero, M.; Terakura, K. Hydration of Alkali Ions from First Principles Molecular Dynamics Revisited. J. Chem. Phys. 2007, 126 (3), 034501.

(40) Remko, M.; Rode, B. M. Effect of Metal Ions $\left(\mathrm{Li}^{+}, \mathrm{Na}^{+}, \mathrm{K}^{+}, \mathrm{Mg}^{2+}\right.$, $\mathrm{Ca}^{2+}, \mathrm{Ni}^{2+}, \mathrm{Cu}^{2+}$, and $\mathrm{Zn}^{2+}$ ) and Water Coordination on the Structure of Glycine and Zwitterionic Glycine. J. Phys. Chem. A 2006, 110 (5), 1960-1967.

(41) Flint, N. J.; Tabner, B. J. Linewidth Alternation, as a Result of Intramolecular Cation Migration, in the Electron Spin Resonance Spectrum of the 1,4-Naphthoquinone Radical Anion. J. Chem. Soc., Faraday Trans. 1 1987, 83 (1), 167-176.

(42) Zhang, G.; Yang, Y.; Zhang, T.; Xu, D.; Lei, Z.; Wang, C.; Liu, G.; Deng, Y. Fe ${ }^{\text {iii }}$ Chelated Organic Anode with Ultrahigh Rate Performance and Ultra-Long Cycling Stability for Lithium-Ion Batteries. Energy Storage Mater. 2020, 24, 432-438.

(43) Đorović, J.; Marković, J. M. D.; Stepanić, V.; Begović, N.; Amić, D.; Marković, Z. Influence of Different Free Radicals on Scavenging Potency of Gallic Acid. J. Mol. Model. 2014, 20 (7), 2345.

(44) Chen, Y.; Xiao, H.; Zheng, J.; Liang, G. StructureThermodynamics-Antioxidant Activity Relationships of Selected Natural Phenolic Acids and Derivatives: An Experimental and Theoretical Evaluation. PLoS One 2015, 10 (3), e0121276-e0121276.

(45) Eslami, A. C.; Pasanphan, W.; Wagner, B. A.; Buettner, G. R. Free Radicals Produced by the Oxidation of Gallic Acid: An Electron Paramagnetic Resonance Study. Chem. Cent. J. 2010, 4, 15.

(46) Janošević, A.; Ćirić-Marjanović, G.; Šljukić Paunković, B.; Pašti, I.; Trifunović, S.; Marjanović, B.; Stejskal, J. Simultaneous Oxidation of Aniline and Tannic Acid with Peroxydisulfate: Self-Assembly of Oxidation Products from Nanorods to Microspheres. Synth. Met. 2012, 162 (9), 843-856.

(47) Scott, A. I. Oxidative Coupling of Phenolic Compounds. Q. Rev., Chem. Soc. 1965, 19 (1), 1-35.

(48) Yoshida, T.; Yoshimura, M.; Amakura, Y. Chemical and Biological Significance of Oenothein B and Related Ellagitannin Oligomers with Macrocyclic Structure. Molecules 2018, 23 (3), 552.

(49) Marković, Z.; Milenković, D.; Đorović, J.; Dimitrić Marković, J. M.; Lučić, B.; Amić, D. A Dft and Pm6 Study of Free Radical Scavenging Activity of Ellagic Acid. Monatsh. Chem. 2013, 144 (6), 803-812.

(50) Dixon, W. T.; Kok, P. M.; Murphy, D. Calculations of G-Factors of Phenoxyl Radicals, Phenol Radical Cations and Alkyl Aryl Ether Radical Cations. J. Chem. Soc., Faraday Trans. 2 1978, 74 (0), 15281531.

(51) Spiegel, M.; Andruniów, T.; Sroka, Z. Flavones' and Flavonols' Antiradical Structure-Activity Relationship-a Quantum Chemical Study. Antioxidants 2020, 9 (6), 461.

(52) Felix, C. C.; Sealy, R. C. O-Benzosemiquinone and Its Metal Chelates. Electron Spin Resonance Investigation of Radicals from the Photolysis of Catechol in the Presence of Complexing Metal Ions. J. Am. Chem. Soc. 1982, 104 (6), 1555-1560. 
(53) Liu, B.; Burdine, L.; Kodadek, T. Chemistry of PeriodateMediated Cross-Linking of 3,4-Dihydroxylphenylalanine-Containing Molecules to Proteins. J. Am. Chem. Soc. 2006, 128 (47), 15228-15235.

(54) Weidman, S. W.; Kaiser, E. T. The Mechanism of the Periodate Oxidation of Aromatic Systems. Iii. A Kinetic Study of the Periodate Oxidation of Catechol. J. Am. Chem. Soc. 1966, 88 (24), 5820-5827.

(55) Malinda, K.; Sutanto, H.; Darmawan, A. Characterization and Antioxidant Activity of Gallic Acid Derivative. AIP Conf. Proc. 2017, 1904 (1), 020030.

(56) Lucken, E. A. C. 814. Ion-Association and Specific Solvation in the Electron Spin Resonance Spectra of Semiquinones. J. Chem. Soc. 1964, 4234-4240.

(57) Ou, R.; Wei, J.; Zhao, C.; Gu, Q.; Zhu, H.; Li, X.; Nguyen, N. S.; Wan, L.; Forsyth, M.; Wang, H. Monovalent Cation-Phenolic Crystals with Ph Reversible Crystal Transformation. Chem. - Eur. J. 2019, 25, 12281-12287.

(58) Simić, A. Z.; Verbić, T. Ž.; Sentić, M. N.; Vojić, M. P.; Juranić, I. O.; Manojlović, D. D. Study of Ellagic Acid Electro-Oxidation Mechanism. Monatsh. Chem. 2013, 144 (2), 121-128.

(59) Kotorlenko, L. A.; Aleksandrova, V. S. Spectral Manifestations of Change in Electronic Structure in Phenol-Phenolate Anion-Phenoxy Radical Series. Theor. Exp. Chem. 1982, 18 (1), 97-99.

(60) Díaz Hidalgo, R. J.; Córdoba, R.; Nabais, P.; Silva, V.; Melo, M. J.; Pina, F.; Teixeira, N.; Freitas, V. New Insights into Iron-Gall Inks through the Use of Historically Accurate Reconstructions. Heritage Sci. 2018, 6 (1), 63.

(61) Brunet, F.; Cabane, B.; Dubois, M.; Perly, B. Sol-Gel Polymerization Studied through Silicon-29 Nmr with Polarization Transfer. J. Phys. Chem. 1991, 95 (2), 945-951.

(62) McCormick, A. V.; Bell, A. T.; Radke, C. J. Evidence from AlkaliMetal Nmr Spectroscopy for Ion Pairing in Alkaline Silicate Solutions. J. Phys. Chem. 1989, 93 (5), 1733-1737.

(63) McCormick, A. V.; Bell, A. T.; Radke, C. J. Influence of AlkaliMetal Cations on Silicon Exchange and Silicon-29 Spin Relaxation in Alkaline Silicate Solutions. J. Phys. Chem. 1989, 93 (5), 1737-1741. 